\title{
Immunomolecular Assay Based on Selective Virion Capture by Spike Antibody and Viral Nucleic Acid Amplification for Detecting Intact SARS-CoV-2 Particles
}

\section{Xiaoli Wu}

Chongqing Medical University

Junye Liu

Chongqing Medical University

Hongpeng Zhang

Department of Laboratory Medicine, Chongqing Health Center for Women and Children

Hua Zhou

The Second Affiliated Hospital of Chongqing Medical University

\section{Wen Wang}

Chongqing Medical University

\section{Yuanyan Ma}

Chongqing Medical University

\section{Shimei Shen}

Chongqing Medical University

\section{Xuefei Cai}

Chongqing Medical University

\section{Ailong Huang}

Chongqing Medical University

\section{Shijia Ding}

Chongqing Medical University

Deqiang Wang ( $\sim$ wangdq@cqmu.edu.cn )

Chongqing Medical University

\section{Method Article}

Keywords: COVID-19, complete virions, Spike, infection risk, immunomolecular detection

Posted Date: February 22nd, 2022

DOI: https://doi.org/10.21203/rs.3.rs-1374603/v1 
License: (c) (i) This work is licensed under a Creative Commons Attribution 4.0 International License. Read Full License 


\section{Abstract}

Background: Effective therapeutics and vaccines for coronavirus disease 2019 (COVID-19) are currently lacking because of the mutation and immune escape of severe acute respiratory syndrome coronavirus 2 (SARS-CoV-2). Based on the propagation characteristics of SARS-CoV-2, rapid and accurate detection of complete virions from clinical samples and the environment is critical for assessing infection risk and containing further COVID-19 outbreaks. However, currently applicable methods cannot achieve large-scale clinical application because of factors such as the high viral load, cumbersome virus isolation steps, demanding environmental conditions, and long experimental periods. In this study, we developed an immunomolecular detection method combining capture of the viral spike glycoprotein with monoclonal antibodies and nucleic acid amplification via quantitative reverse transcription PCR to rapidly and accurately detect complete virions.

Results: After constructing a novel pseudovirus, screening for specific antibodies, and optimizing the detection parameters, the assay achieved a limit of detection of $9 \times 10^{2}$ transduction units $/ \mathrm{mL}$ of viral titer with high confidence $(\sim 95 \%)$ and excellent stability against human serum and common virus/pseudovirus. The coefficients of variation were 1.0-2.0\% for intra-assay and inter-assay analyses, respectively. Compared with reverse transcription-PCR, the immunomolecular method more accurately quantified complete virions. SARS-CoV-2/pseudovirus was more stable on plastic and paper than on aluminum and copper in the detection of SARS-CoV-2 pseudovirus under different conditions, and complete virions were detected up to $96 \mathrm{~h}$ after they were applied to these surfaces (except for copper), although the titer of the virions was greatly reduced.

Conclusions: Convenient, inexpensive, and accurate complete virus detection can be applied in many fields, such as monitoring the infectivity of convalescent and post-discharge patients and assessing highrisk environments (isolation rooms, operating rooms, patient living environments, and cold chain logistics). This method can also be used to detect intact virions such as those of hepatitis B and C viruses, human immunodeficiency virus, influenza, and the partial pulmonary virus, which may further improve the accuracy of diagnoses and facilitate individualized and precise treatments.

\section{Background}

Coronavirus disease 2019 (COVID-19), caused by the novel coronavirus severe acute respiratory syndrome coronavirus 2 (SARS-CoV-2), has developed into a serious global public health threat[1, 2]. Despite the extensive financial investments in the diagnosis, treatment, and prevention of COVID-19, the pandemic is ongoing because of the high infectivity, pathogenicity, mutation and immune escape of SARS-CoV-2[3-6].

The novel $\beta$-coronavirus, SARS-CoV-2, contains a single-strand positive-sense RNA genome of 30 kilobases containing five major open reading frames (ORFs): replicase complex (ORF1ab), spike (S), envelope $(E)$, membrane $(M)$, and nucleocapsid $(N)$, and is approximately $80-120 \mathrm{~nm}$ in diameter[7-9]. 
SARS-CoV-2 enters and infects the host cell via the S protein on the outer viral membrane by interacting with the host receptor human angiotensin-converting enzyme 2 (hACE2)[10-12]. The positive singlestranded RNA is released from the virus and moves into the cell nucleus, where nonstructural proteins, viral polymerases, RNA, and viral structural proteins are synthesized sequentially. These components are then packaged into new complete virion particles. The progeny virus is wrapped in a vesicle in the cytoplasm and released from the cell through exocytosis to begin the next viral cycle of infection[13]. Analogously, the nucleocapsid protein can form condensates with viral genomic RNA which are secreted extracellularly as "subviral particles and is a common occurrence in the life cycle of human viruses[1416]. For example, the core protein and viral DNA of hepatitis B virus (HBV) can assemble as capsid particles that are secreted, and the capsid protein (CA) of human immunodeficiency virus (HIV) and core protein of hepatitis $C$ virus can coat viral RNA and emit it as sub-virus particles[17-20]. Based on the life cycle of SARS-CoV-2, intact virus particles clearly represent the only elements that sustain infection, whereas subviral particles cannot sustain the viral life cycle consistently enough to persistently infect the host.

According to previous studies, human-to-human transmission via respiratory droplets and close contact is the main transmission route of SARS-CoV-2[21, 22]. However, some cold chain practitioners have been infected via contact with contaminated cold chain goods globally; therefore, contact with objects contaminated by SARS-CoV-2 may also cause infection[23-25]. Recent studies reported that positive results for COVID-19 were detected in blood samples of convalescent patients and different environmental conditions, including cold-chain logistics, hospital rooms, and airtight cabins[26-31]. Whether positive signals indicate that the patient or environment is at a high risk of infection, as well as the influence of subviral particles and free RNA fragments, requires further analysis.

Several methods have been developed to ensure the timely and effective detection of SARS-CoV-2 infection, including pathology-based chest computed tomography, protein-based viral antigens, and antibody detection and nucleic acid-based RNA detection[32-41]. These assays are important for diagnosing coronavirus infections and forming clinical treatment prognoses[42]. However, some "subviral particles" are either missing both the genome and capsid or missing only the genome, resulting in falsepositive detection signals that do not truly reflect the viral replication and infection abilities. For example, HBV subviral particles composed of only viral surface proteins are present in the blood of infected individuals at up to a 100,000-fold excess compared to complete virions (at 1014/mL). Empty (genomefree) virions, which contain the surface proteins enclosing the viral capsid but no genome, exhibit 100 fold higher levels over complete virions in the blood of infected individuals $\left(10^{11} / \mathrm{mL}\right)^{[43-46]}$. Therefore, detecting intact SARS-CoV-2 particles in body fluid (including blood, saliva, etc)and the environment is critical for assessing infection risk and containing further outbreaks of COVID-19.

Using pseudoviruses enables research of highly pathogenic viruses without the requirement for highly secure biosafety facilities, which has greatly benefited research on COVID-19[47-50]. However, the previously reported SARS-CoV-2-related recombinant virus either simulated the functional structure of $S$ and $\mathrm{N}$ protein or incorporated fragments of its nucleic acids, and failed to simulate the functional 
structure of complete SARS-CoV-2 particles. Here, we constructed a SARS-CoV-2 pseudovirus system to simulate the functional structure of SARS-CoV-2 and obtained monoclonal antibodies with high affinity through screening of 11 strains of specific antibodies directed to $S$ proteins. An immunomolecular assay was developed by combining immunocapturing SARS-CoV-2 spike protein and nucleic acid amplification via quantitative reverse transcription polymerase chain reaction (RT-qPCR) for highly sensitive and selective detection of intact SARS-CoV-2 particles.

\section{Results}

\section{Construction of pseudo-SARS-CoV-2 virus and screening of specific antibodies directed to Spike glycoproteins}

To simulate the functional structure of intact SARS-Cov-2 particles, we constructed a SARS-CoV-2 pseudovirus expressing the Spike glycoproteins outside the envelope and incorporating four viral uncompleted genes of SARS-CoV-2 (ORF1ab, ORFab, $\mathrm{N}$, and $\mathrm{M}$ ) into the lentivirus encoding green fluorescence protein (GFP) (Figure 1a). A lentivirus-transformed plasmid, pLV-SARS-CoV-2-F1abFabNEGFP, and an envelope plasmid, pCMV3-2019-nCoV-Spike (S1+S2), were constructed first (Figure S1). After generating SARS-CoV-2 pseudoviruses through co-transfection, we tested their infectivity by transducing HEK-293FT-hACE2 cells (Figure S2). Abundant GFP fluorescence was observed via fluorescence microscopy at 48 and $72 \mathrm{~h}$, suggesting successful construction and transduction of the pseudovirus (Figure 1b). The efficiency of incorporating the SARS-CoV-2 $\mathrm{S}$ protein and targeted sequence into the lentiviral cells was evaluated using monoclonal mouse anti-S (S2 domain) via western blotting and qRTPCR targeted to the F1ab gene, respectively (Figure 1c and 1d). Specific bands at 190 and $80 \mathrm{kDa}$ corresponded to the monomer S protein $(\mathrm{S} 1+\mathrm{S} 2)$ and $\mathrm{S} 2$ domains, respectively (Figure 1c, lane 3 ), and the positive signal for the F1ab gene supported the functional integrity of the SARS-CoV-2 pseudovirus.

Based the SARS-CoV-2 pseudovirus, 11 monoclonal antibodies (CQ2, CQ20, CQ25, CQ8, CQ12, CQ001, CQ100, CQ040, CQ042, CQ023, and M1E1) directed to the Spike glycoproteins of SARS-CoV-2 were prepared and screened according to their affinity using western blotting and particle gel assay[51]. Influenced by its natural shape and charge, the active Spike glycoproteins of SARS-CoV-2 only could be detected with the CQ2, CQ25, and M1E1 antibodies (Figure 1e and 1f). Among these 11 candidates, the CQ25 antibodies showed excellent affinity and specificity for S protein.

\section{Immunomolecular detection platform for SARS-CoV-2/pseudovirus particles}

After preparing the SARS-CoV-2 pseudovirus and high-affinity antibodies, an immunomolecular detection platform for intact SARS-CoV-2/pseudovirus was designed. In summary, carboxyl groups were coated on the surface of nanomagnetic beads that were covalently bound to the amino groups of the antibodies to form peptide bonds, resulting in the generation of magnetic beads-antibodies complexes. After coincubation at $20 \sim 25^{\circ} \mathrm{C}$, anti-S antibodies-magnetic bead complexes specifically captured the SARS-CoV$2 /$ pseudovirus particles. Following separation of the supernatant using a magnetic separator, the SARSCoV-2/pseudovirus particles were enriched and separated from other "subviral particles" without S 
glycoprotein and free RNA fragments. Finally, nucleic acid-based detection via qRT-PCR excluded the influence of empty (genome-free) virions to further ensure that the detection platform only targeted intact SARS-CoV-2/pseudovirus particles (Figure 2a).

To establish an immunomolecular detection platform for intact SARS-CoV-2 particles, carboxyl magnetic beads and anti-S antibody (CQ25) were coupled. The effect of conjugation was evaluated by measuring the protein concentration of the complexes following conjugation using a BCA assay (Figure 2b) and particle size analysis (Figure 2c). Compared with untreated carboxyl magnetic beads, the complexes showed much higher absorption intensities (approximately 10-fold) at $562 \mathrm{~nm}$ and much larger average effective diameters (approximately 2 -fold), indicating that the anti-S antibodies were successfully conjugated with the magnetic beads. The complexes and corresponding supernatant were subjected to sodium dodecyl sulfate-polyacrylamide gel electrophoresis (SDS-PAGE) followed by Coomassie bright blue staining, which confirmed the successful coupling and optimization of the coupling parameters (Figure 2d). Next, we verified whether the SARS-CoV-2 pseudovirus could be captured by anti-S antibodymagnetic beads complexes (MB-CQ25) at the protein and nucleic acid levels. Because HIV1 P24 is the most abundant marker protein in the lentivirus capsid, we identified the viral capsid proteins of captured virions in a viral particle gel assay with the monoclonal mouse anti-HIV 1 p24 antibody. As shown in Figure 2e, specific bands were observed in the complexes following capture. Importantly, compared with the negative control samples, including the SARS-CoV-2 S pseudovirus, VSV-G pseudovirus, and HBV, only our SARS-CoV-2 pseudovirus generated a positive signal via nucleic acid-based detection following capture (Figure 2f). These results show that the immunomolecular detection platform specifically detected intact SARS-CoV-2/pseudovirus particles.

\section{Immunomolecular assay detects only intact virus particles}

To verify the detection target of the immunomolecular assay, sucrose density gradient ultracentrifugation was performed to isolate the pseudovirus particles[46]. As shown in Figure. 3a, the $\mathrm{S}$ glycoprotein peaked in the $10-20 \%$ sucrose gradient according to western blot analysis, whereas the pseudovirus particles settled at the $40 \%$ sucrose gradient in the gel assay, suggesting the presence of abundant free $S$ proteins (large excess over complete virions) in the cell supernatant. Additionally, qRT-PCR and immunomolecular assays were used to determine the RNA levels of total and intact virions in different density gradients. The data indicated that pseudovirus particles were enriched in the $40 \%$ sucrose gradient fraction. Nevertheless, the virogene level was significantly higher than that of the intact virion $(P<0.05)$, suggesting that some subviral particles (without $S$ envelope proteins) were produced during virus packaging; these results are consistent with previous reports on $\mathrm{HBV}[44,45]$. Using different titers of intact virions to transduce 293FT-HEK-hACE2 cells, we found that the titer of intact virions detected in the immunomolecular assay was positively correlated with infectivity, suggesting that the detection target of the immunomolecular assay is intact virus particles (Figure $3 b$ ).

\section{Validation of immunomolecular assay for intact SARS-CoV-2 particles}


After optimizing the detection conditions, ten-fold gradient dilutions were prepared and analyzed using fluorescence qRT-PCR in parallel to determine the linear range (Figure S3). When the titer ranged between $6 \times 10^{2}$ and $6 \times 10^{7}$ transduction units $(\mathrm{TU}) / \mathrm{mL}$, there was a linear relationship between the Cq value and its titer ( $\log _{10}$ transformed) in the immunomolecular assay $\left(R^{2}=0.99\right)$ (Figure $\left.4 a\right)$. As shown in Figure 4b, there were significant differences between the negative samples with the 24 carboxy magnetic beads coupled with CQ25 antibodies (MB) and positive samples containing 24 instances of captured pseudovirus $(P<0.0001)$. Using a mean titer of the negative samples of +1.96 standard deviation, the limit of detection was $900 \mathrm{TU} / \mathrm{mL}$. Although the Cq value could be measured when the pseudovirus titer was lower than $900 \mathrm{TU} / \mathrm{mL}$, the results of fluorescence quantitative PCR were negative.

Human serum contains a large amount of albumin and various antibodies, which may affect the assay stability. Additionally, if the patient carries other non-specific viruses, the specificity and stability of the method may be affected. To evaluate these factors, the HBV supernatant collected from AD38 cells and patient serum with different titers of HBV were used to verify the anti-interference ability of this immunomolecular assay. As shown in Figure 4c, for the low-titer group, adding HBV and patient serum with different titers of HBV had a negligible effect on the quantitative qualitative detection rate of intact SARS-CoV-2 pseudovirus particles, with coefficients of variation of $1.5 \%$ and $2.0 \%$ for intra-assay and inter-assay analyses, respectively; those of the high-titer group were $1.4 \%$ and $1.0 \%$. Thus, this method is significantly stable against non-specific viruses and human serum. We further examined the stability of the SARS-CoV-2 pseudovirus over time on various surfaces, including copper, aluminum, paper, and plastic, to mimic different environmental samples (Figure 4d). SARS-CoV-2 was more stable on plastic, aluminum, and paper than on copper, and viable virus was detected up to $96 \mathrm{~h}$ after application to these surfaces; however, the virion titers were greatly reduced (from $10^{7.38}$ to $10^{4.05} \mathrm{TU} / \mathrm{mL}$ on aluminum, from $10^{7.38}$ to $10^{4.58} \mathrm{TU} / \mathrm{mL}$ on paper, and from $10^{7.38}$ to $10^{4.84} \mathrm{TU} / \mathrm{mL}$ on plastic). Notably, although the total RNA produced a positive detection signal, live virus was not detected on the copper surface at $72 \mathrm{~h}$. Moreover, the gap in the titer between the total RNA and intact virions increased over time under different conditions. These results suggest that RNA fragments had different stabilities under different conditions after the complete virions were degraded, supporting RNA levels alone should not be used to assess infection risk.

\section{Discussion}

The COVID-19 pandemic has caused an unprecedented world public health crisis. Currently, effective therapeutics for COVID-19 are lacking, and vaccine development and application cannot keep pace with the high mutation rate of SARS-CoV-2. The diagnosis of SARS-CoV-2 is critical for controlling the spread of COVID-19. Traditional detection methods based on nucleic acid fragments or protein are affected by "subviral particles," such as free RNA fragments, free antigens, nucleocapsid protein-RNA condensates, and empty virions, and thus have failed to provide an accurate basis for patient medication and environmental assessment. Previously, a platform coupled to Raman spectroscopy was used to capture viruses based on their size; however, the nonspecific and harsh experimental conditions prevented 
application of this approach in clinical laboratories[52]. The median tissue culture infective dose was also used to quantify virus titers and assess infectivity. However, the high viral load, cumbersome virus isolation steps, demanding environmental conditions, and long experimental periods made it difficult to apply this method in clinical laboratories[53-55]. As free antigens in the supernatant are present in much greater excess over complete virions, detection of viral particles based on viral antigens cannot completely reflect the infection risk of patients and the environment[37, 39]. Here, we developed an immunomolecular assay for detecting intact SARS-CoV-2 particles. This method achieved excellent stability and specificity against other common human virus/pseudovirus and excellent accuracy and convenience for detecting intact SARS-CoV-2 particles in environmental samples. Compared to previously reported pseudoviruses, our designed pseudo-SARS-CoV-2 virus better simulated intact SARS-CoV-2 particles at the nucleic acid and protein level. Four fragments of viral RNA sequences, ORF1ab (1541515540), ORFab (12750-13491), N gene (28750-29150), and E gene (26360-26381), wrapped in the genome of the pseudovirus can be detected using all nucleic acid detection reagents recommended by the World Health Organization and may be sold on the market without redesigning the primers used in qRT-PCR. In addition, compared with previously reported SARS-CoV-2 biomimetic virus-like particles with $\sim 16 \%$ variation, our novel pseudovirus shows much higher stability and may serve as a quantitative diagnostic tool for SARS-CoV-2 (Figure S4)[56].

This assay can be used in a variety of scenarios, such as for monitoring the infectivity of convalescent and post-discharge patients and assessing the risk of infection in high-risk environments including virus detection sampling houses, international flight cabins, and international cold-chain logistics bases. For research and applications, affinity antibodies and carboxyl magnetic beads can be optimized to improve the detection sensitivity. Moreover, isothermal nucleic acid amplification methods may be combined with this detection method to further simplify the experimental process and reduce professional dependence on experimental equipment, enabling applications of this method in clinical practice. This immunomolecular assay can also be used to detect other intact virus particles such as HBV, hepatitis $C$ virus, HIV, influenza, and the partial pulmonary virus, which may improve the accuracy of diagnoses of these infectious diseases and facilitate individualized and precise treatments. However, the potential applications for detecting these intact virus particles require further experimental studies.

\section{Conclusions}

We prepared pseudovirus that fully simulates the SARS-CoV-2 virus in a safe and convenient manner. After screening monoclonal antibodies with high affinity for $\mathrm{S}$ protein, we developed an immunomolecular assay combined immunocaptured of SARS-CoV-2 S protein and nucleic acid amplification via qRT-PCR for highly sensitive and selective detection of intact SARS-CoV-2 particles. This method enables accurate assessment of the contagiousness of infected patients and/or potential infection hazard in high-risk environments.

\section{Methods}




\section{Production and titration of pseudoviruses}

A plasmid containing partial sequences of the SARS-CoV-2 ORF1ab gene, $\mathrm{N}$ gene, $\mathrm{E}$ gene, and GFP reporter was constructed and named as PLV-SARS-CoV-2-F1abMEN-GFP. Pseudoviruses were produced and titrated using methods similar to the Rift Valley Fever pseudovirus, as previously described ${ }^{[57]}$. Briefly, HEK-293FT cells were transfected with the plasmids pCMV3-2019-nCoV-Spike(S1+S2), pLV-SARS-CoV-2F1abFabME-GFP, and pMD2.G (Sino Biological, Inc. Beijing, China) using Lipofectamine 8000 (C0533, Beyotime Biotechnology, Shanghai, China). The virus supernatant was collected and mixed at 48 and 72 $\mathrm{h}$ after transfection and centrifuged at $4{ }^{\circ} \mathrm{C}$ at $4000 \times g$ for $10 \mathrm{~min}$ to remove cell debris. The culture supernatant was placed on a $20 \%$ sucrose solution and centrifuged at 25,000 rpm $(112,000 \times g)$ for $15 \mathrm{~h}$ at $4{ }^{\circ} \mathrm{C}$ in a Beckman SW28 rotor (Beckman Coulter, Brea, CA, USA). For this HIV 1 pseudovirus system, the titer of PsVs was quantified using an HIV-1 Gag p24 DuoSet ELISA kit (KIT11695, Sino Biological Inc. Beijing, China) according to the manufacturer's instructions.

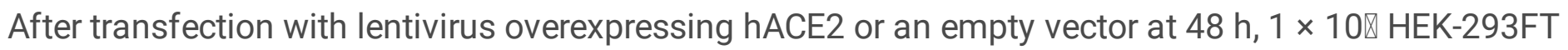
cells in a 96-well plate were transduced with the SARS-CoV-2 pseudovirus and control pseudovirus encoding GFP at a multiplicity of infection of $2 \mathrm{vp} /$ cell for $24 \mathrm{~h}$ at $37^{\circ} \mathrm{C}$. Infection was visualized using a fluorescence microscope at 48 and $72 \mathrm{~h}$.

\section{Conjugation of carboxyl magnetic beads with antibody}

After continuous activation with N-hydroxysuccinimide and 1-ethyl-3-(3-dimethylaminopropyl) carbodiimide solution at $25^{\circ} \mathrm{C}$ for 30 min, carboxymethyl magnetic beads (MSP-COOH-F1 18030106, FlyW\&Y Bio, Chongqing, China) were added to the diluted CQ25 antibodies, mixed, and gently rotated at 4 ${ }^{\circ} \mathrm{C}$ for $4 \mathrm{~h}$. The magnetic bead-antibody complexes and supernatant were separated using a magnetic separator. The complexes were blocked gently with a $1 \%$ bovine serum albumin solution at $25^{\circ} \mathrm{C}$ for 30 min. SDS-PAGE and Coomassie blue staining were performed to evaluate the coupling effect using coupled magnetic beads and separate the supernatants.

\section{qRT-PCR}

SARS-CoV-2 RNA levels were detected using qRT-PCR on a CFX96 system (Bio-Rad, Hercules, CA, USA) using a 2019-nCoV nucleic acid detection kit (fluorometric real-time PCR) (001, Sansure Bio, Hunan, China). Each sample was evaluated in triplicate, and two no-template control wells were included to confirm that there was no contamination.

\section{Western blotting}

The samples were mixed with $6 \times$ SDS sample buffer, boiled for $10 \mathrm{~min}$ at $95^{\circ} \mathrm{C}$, and subjected to SDSPAGE and immunoblotting. The pseudovirus was detected using mouse/human anti-S/membrane antibodies (CQ2, CQ20, CQ25, CQ8, CQ12, CQ001, CQ100, CQ040, CQ042, CQ023, and M1E1, a gift from the Laboratory of Molecular Biology of Infectious Diseases, Chongqing Medical University, Chongqing, 
China) at a 1:1000 dilution. Goat anti-mouse lgG (No. SA00003-1, Proteintech, Rosemont, IL, USA) was used at a 1:4000 dilution as the secondary antibody.

\section{Viral particle gel}

Denatured samples were resolved on a $1 \%$ agarose gel in $1 \times$ TAE buffer at $70 \mathrm{~V}$ for $2 \mathrm{~h}$. Particles in the gel were transferred to a nylon membrane in $1 \times$ TBE buffer for $12 \mathrm{~h}$ based on the Siphon principle[51]. After transfer, the membrane was blocked in $5 \%$ bovine serum albumin for 30 min and incubated in an antiHIV-1 P24 antibody solution or anti-S antibody solution for $12 \mathrm{~h}$ at $4{ }^{\circ} \mathrm{C}$. The membranes were exposed following washing with $1 \times$ Tris-buffered saline containing $1 \%$ o Tween 20 .

\section{Particle size analysis}

The effective particle size of the carboxyl magnetic beads (MB) and magnetic beads-CQ25 antibody complex (MB-CQ25) were characterized using a NanoBrook 90PLUS PALS particle size analyzer (Brookhaven Instruments Corporation, Holtsville, NY, USA). The sample was added to pure water (1\%o Triton-100) and mixed to ensure even dispersion in the medium. If necessary, the sample was sonicated for $15 \mathrm{~min}$. The particle size was determined after setting the parameters according to the instrument manual. Three complex holes were placed each time, and this process was repeated twice. The data were analyzed and plotted using GraphPad Prism 8 software (GraphPad Inc., San Diego, CA, USA).

\section{Sucrose density gradient ultracentrifugation}

Sucrose density gradient centrifugation was performed as previously described[46]. Briefly, discontinuous sucrose density gradients $(10 \%, 20 \%, 30 \%, 40 \%, 50 \%$, and $60 \%)$ were prepared in PBS. The culture supernatant was laid on the linear sucrose gradient and centrifuged at 25,000 rpm $(112,000 \times g)$ for $15 \mathrm{~h}$ at $4{ }^{\circ} \mathrm{C}$ in a SW28 rotor (Beckman Coulter).

\section{Statistical analyses}

Linear regression, descriptive statistics, repeated measures analysis of variance, and two groups of unpaired $t$-tests were performed using the statistical software package SPSS version 21.0 for Windows (SPSS Inc., Chicago, IL, USA). All tests of significance were two-tailed, and statistical significance was set at $\mathrm{P}<0.05$.

\section{Declarations}

\section{Ethics approval and consent to participate}

Not applicable.

\section{Consent for publication}

Not applicable. 
Availability of data and materials

All data generated or analyzed during this study are included in the article.

\section{Competing interests}

The authors declare that they have no competing interests.

\section{Funding}

This work was supported by grants from the National Science and Technology Major Project (2017ZX10202203 and 2018ZX10732202) (to AH), the Chongqing Natural Science Foundation (CSTC2018jscx-msybX0032 and CSTC2016jcyjA0204) (to DW), and the Natural Science Foundation of Chongqing Yuzhong (20190145) (to DW).

\section{Authors' contributions}

X. L, J. L, and H. Z contributed equally to this work.

\section{Acknowledgements}

We thank Prof. Aishun Jin (Department of Immunology, Chongqing Medical University, China) for providing some antibodies. We would like to thank Editage (www.editage.cn) for its linguistic assistance during the preparation of this manuscript.

\section{References}

1. Wang C, Horby PW, Hayden FG, Gao GF: A novel coronavirus outbreak of global health concern. Lancet 2020, 395(10223):470-473.

2. Dong E, Du H, Gardner L: An interactive web-based dashboard to track COVID-19 in real time. Lancet Infect Dis 2020, 20(5):533-534.

3. Tregoning JS, Flight KE, Higham SL, Wang Z, Pierce BF: Progress of the COVID-19 vaccine effort: viruses, vaccines and variants versus efficacy, effectiveness and escape. Nat Rev Immunol 2021, 21(10):626-636.

4. Garcia-Beltran WF, Lam EC, St Denis K, Nitido AD, Garcia ZH, Hauser BM, Feldman J, Pavlovic MN, Gregory DJ, Poznansky MC et al: Multiple SARS-CoV-2 variants escape neutralization by vaccineinduced humoral immunity. Cell 2021, 184(9):2372-2383.e2379.

5. Grubaugh ND, Hodcroft EB, Fauver JR, Phelan AL, Cevik M: Public health actions to control new SARS-CoV-2 variants. Cell 2021, 184(5):1127-1132.

6. Li Q, Nie J, Wu J, Zhang L, Ding R, Wang H, Zhang Y, Li T, Liu S, Zhang M et al: SARS-CoV-2 501Y.V2 variants lack higher infectivity but do have immune escape. Cell 2021, 184(9):2362-2371.e2369. 
7. Klein S, Cortese M, Winter SL, Wachsmuth-Melm M, Neufeldt CJ, Cerikan B, Stanifer ML, Boulant S, Bartenschlager R, Chlanda P: SARS-CoV-2 structure and replication characterized by in situ cryoelectron tomography. Nat Commun 2020, 11(1):5885.

8. Lu R, Zhao X, Li J, Niu P, Yang B, Wu H, Wang W, Song H, Huang B, Zhu N et al: Genomic characterisation and epidemiology of 2019 novel coronavirus: implications for virus origins and receptor binding. Lancet 2020, 395(10224):565-574.

9. Hu B, Guo H, Zhou P, Shi ZL: Characteristics of SARS-CoV-2 and COVID-19. Nat Rev Microbiol 2021, 19(3):141-154.

10. Hoffmann M, Kleine-Weber H, Schroeder S, Krüger N, Herrler T, Erichsen S, Schiergens TS, Herrler G, Wu NH, Nitsche A et al: SARS-CoV-2 Cell Entry Depends on ACE2 and TMPRSS2 and Is Blocked by a Clinically Proven Protease Inhibitor. Cell 2020, 181(2):271-280.e278.

11. Li W, Moore MJ, Vasilieva N, Sui J, Wong SK, Berne MA, Somasundaran M, Sullivan JL, Luzuriaga K, Greenough TC et al: Angiotensin-converting enzyme 2 is a functional receptor for the SARS coronavirus. Nature 2003, 426(6965):450-454.

12. Shang J, Ye G, Shi K, Wan Y, Luo C, Aihara H, Geng Q, Auerbach A, Li F: Structural basis of receptor recognition by SARS-CoV-2. Nature 2020, 581(7807):221-224.

13. Oberfeld B, Achanta A, Carpenter K, Chen P, Gilette NM, Langat P, Said JT, Schiff AE, Zhou AS, Barczak AK et al: SnapShot: COVID-19. Cell 2020, 181(4):954-954.e951.

14. Lu S, Ye Q, Singh D, Cao Y, Diedrich JK, Yates JR, Villa E, Cleveland DW, Corbett KD: The SARS-CoV-2 nucleocapsid phosphoprotein forms mutually exclusive condensates with RNA and the memb raneassociated M protein. Nat Commun 2021, 12(1):502.

15. Perdikari TM, Murthy AC, Ryan VH, Watters S, Naik MT, Fawzi NL: SARS-CoV-2 nucleocapsid protein phase-separates with RNA and with human hnRNPs. Embo j 2020, 39(24):e106478.

16. Savastano A, lb" $c$ ?ez de Opakua A, Rankovic M, Zweckstetter M: Nucleocapsid protein of SARS-CoV2 phase separates into RNA-rich polymerase-containing condensates. Nat Commun 2020, 11(1):6041.

17. Mattei S, Glass B, Hagen WJ, Kräusslich HG, Briggs JA: The structure and flexibility of conical HIV-1 capsids determined within intact virions. Science 2016, 354(6318):1434-1437.

18. Qu K, Glass B, Doležal M, Schur FKM, Murciano B, Rein A, Rumlová M, Ruml T, Kräusslich HG, Briggs JAG: Structure and architecture of immature and mature murine leukemia virus capsids. Proc Natl Acad Sci U S A 2018, 115(50):E11751-e11760.

19. Holmstrom ED, Nettels D, Schuler B: Conformational Plasticity of Hepatitis C Virus Core Protein Enables RNA-Induced Formation of Nucleocapsid-like Particles. J Mol Biol 2018, 430(16):24532467.

20. Blondot ML, Bruss V, Kann M: Intracellular transport and egress of hepatitis B virus. J Hepatol 2016, 64(1 Suppl):S49-s59.

21. Chan JF, Yuan S, Kok KH, To KK, Chu H, Yang J, Xing F, Liu J, Yip CC, Poon RW et al: A familial cluster of pneumonia associated with the $\mathbf{2 0 1 9}$ novel coronavirus indicating person-to-person transmission: 
a study of a family cluster. Lancet 2020, 395(10223):514-523.

22. Chen N, Zhou M, Dong X, Qu J, Gong F, Han Y, Qiu Y, Wang J, Liu Y, Wei Y et al: Epidemiological and clinical characteristics of 99 cases of 2019 novel coronavirus pneumonia in Wuhan, China: a descriptive study. Lancet 2020, 395(10223):507-513.

23. Liu P, Yang M, Zhao X, Guo Y, Wang L, Zhang J, Lei W, Han W, Jiang F, Liu WJ et al: Cold-chain transportation in the frozen food industry may have caused a recurrence of COVID-19 cases in destination: Successful isolation of SARS-CoV-2 virus from the imported frozen cod package surface. Biosaf Health 2020, 2(4):199-201.

24. Ma H, Zhang J, Wang J, Qin Y, Chen C, Song Y, Wang L, Meng J, Mao L, Li F et al: COVID-19 Outbreak Caused by Contaminated Packaging of Imported Cold-Chain Products - Liaoning Province, China, July 2020. China CDC Wkly 2021, 3(21):441-447.

25. Xie C, Zhao H, Li K, Zhang Z, Lu X, Peng H, Wang D, Chen J, Zhang X, Wu D et al: The evidence of indirect transmission of SARS-CoV-2 reported in Guangzhou, China. BMC Public Health 2020, 20(1):1202.

26. Chia PY, Coleman KK, Tan YK, Ong SWX, Gum M, Lau SK, Lim XF, Lim AS, Sutjipto S, Lee PH et al: Detection of air and surface contamination by SARS-CoV-2 in hospital rooms of infected patients. Nat Commun 2020, 11(1):2800.

27. Harvey AP, Fuhrmeister ER, Cantrell ME, Pitol AK, Swarthout JM, Powers JE, Nadimpalli ML, Julian TR, Pickering AJ: Longitudinal Monitoring of SARS-CoV-2 RNA on High-Touch Surfaces in a Community Setting. Environ Sci Technol Lett 2021, 8(2):168-175.

28. Liu H, Fei C, Chen Y, Luo S, Yang T, Yang L, Liu J, Ji X, Wu W, Song J: Investigating SARS-CoV-2 persistent contamination in different indoor environments. Environ Res 2021, 202:111763.

29. Somsen GA, van Rijn C, Kooij S, Bem RA, Bonn D: Small droplet aerosols in poorly ventilated spaces and SARS-CoV-2 transmission. Lancet Respir Med 2020, 8(7):658-659.

30. Santarpia JL, Rivera DN, Herrera VL, Morwitzer MJ, Creager HM, Santarpia GW, Crown KK, Brett-Major DM, Schnaubelt ER, Broadhurst MJ et al: Author Correction: Aerosol and surface contamination of SARS-CoV-2 observed in quarantine and isolation care. Sci Rep 2020, 10(1):13892.

31. Zhou J, Otter JA, Price JR, Cimpeanu C, Meno Garcia D, Kinross J, Boshier PR, Mason S, Bolt F, Holmes AH et al: Investigating Severe Acute Respiratory Syndrome Coronavirus 2 (SARS-CoV-2) Surface and Air Contamination in an Acute Healthcare Setting During the Peak of the Coronavirus Disease 2019 (COVID-19) Pandemic in London. Clin Infect Dis 2021, 73(7):e1870-e1877.

32. Chung M, Bernheim A, Mei X, Zhang N, Huang M, Zeng X, Cui J, Xu W, Yang Y, Fayad ZA et al: CT Imaging Features of 2019 Novel Coronavirus (2019-nCoV). Radiology 2020, 295(1):202-207.

33. Zhang C, Zhou L, Liu H, Zhang S, Tian Y, Huo J, Li F, Zhang Y, Wei B, Xu D et al: Establishing a high sensitivity detection method for SARS-CoV-2 IgM/lgG and developing a clinical application of this method. Emerg Microbes Infect 2020, 9(1):2020-2029.

34. Corman VM, Landt O, Kaiser M, Molenkamp R, Meijer A, Chu DK, Bleicker T, Br"nink S, Schneider J, Schmidt ML et al: Detection of 2019 novel coronavirus (2019-nCoV) by real-time RT-PCR. Euro 
Surveill 2020, 25(3).

35. Joung J, Ladha A, Saito M, Kim NG, Woolley AE, Segel M, Barretto RPJ, Ranu A, Macrae RK, Faure G et al: Detection of SARS-CoV-2 with SHERLOCK One-Pot Testing. N Engl J Med 2020, 383(15):14921494.

36. Broughton JP, Deng X, Yu G, Fasching CL, Servellita V, Singh J, Miao X, Streithorst JA, Granados A, Sotomayor-Gonzalez A et al: CRISPR-Cas12-based detection of SARS-CoV-2. Nat Biotechnol 2020, 38(7):870-874.

37. Seo G, Lee G, Kim MJ, Baek SH, Choi M, Ku KB, Lee CS, Jun S, Park D, Kim HG et al: Rapid Detection of COVID-19 Causative Virus (SARS-CoV-2) in Human Nasopharyngeal Swab Specimens Using FieldEffect Transistor-Based Biosensor. ACS Nano 2020, 14(4):5135-5142.

38. Alafeef M, Dighe K, Moitra P, Pan D: Rapid, Ultrasensitive, and Quantitative Detection of SARS-CoV-2 Using Antisense Oligonucleotides Directed Electrochemical Biosensor Chip. ACS Nano 2020.

39. Nguyen NHL, Kim S, Lindemann G, Berry V: COVID-19 Spike Protein Induced Phononic Modification in Antibody-Coupled Graphene for Viral Detection Application. ACS Nano 2021.

40. Xia Y, Chen Y, Tang Y, Cheng G, Yu X, He H, Cao G, Lu H, Liu Z, Zheng SY: Smartphone-Based Point-ofCare Microfluidic Platform Fabricated with a ZnO Nanorod Template for Colorimetric Virus Detection. ACS Sens 2019, 4(12):3298-3307.

41. Chen KL, Yang ZY, Lin CW: A magneto-optical biochip for rapid assay based on the Cotton-Mouton

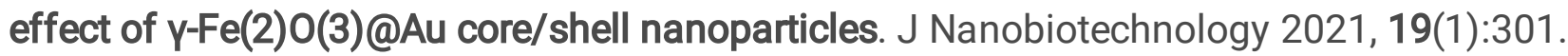

42. Wiersinga WJ, Rhodes A, Cheng AC, Peacock SJ, Prescott HC: Pathophysiology, Transmission, Diagnosis, and Treatment of Coronavirus Disease 2019 (COVID-19): A Rev iew. Jama 2020, 324(8):782-793.

43. Blumberg BS: Australia antigen and the biology of hepatitis B. Science 1977, 197(4298):17-25.

44. Luckenbaugh L, Kitrinos KM, Delaney WEt, Hu J: Genome-free hepatitis B virion levels in patient sera as a potential marker to monitor response to antiviral therapy. J Viral Hepat 2015, 22(6):561-570.

45. Ning X, Nguyen D, Mentzer L, Adams C, Lee H, Ashley R, Hafenstein S, Hu J: Secretion of genome-free hepatitis $B$ virus-single strand blocking model for virion morphogenesis of para-retrovirus. PLoS Pathog 2011, 7(9):e1002255.

46. Wang J, Shen T, Huang X, Kumar GR, Chen X, Zeng Z, Zhang R, Chen R, Li T, Zhang T et al: Serum hepatitis $B$ virus RNA is encapsidated pregenome RNA that may be associated with persistence of viral infection and rebound. J Hepatol 2016, 65(4):700-710.

47. Yu J, Li Z, He X, Gebre MS, Bondzie EA, Wan H, Jacob-Dolan C, Martinez DR, Nkolola JP, Baric RS et al: Deletion of the SARS-CoV-2 Spike Cytoplasmic Tail Increases Infectivity in Pseudovirus Neutralization Assays. J Virol 2021, 95(11).

48. Chen M, Zhang XE: Construction and applications of SARS-CoV-2 pseudoviruses: a mini review. Int J Biol Sci 2021, 17(6):1574-1580. 
49. Ou X, Liu Y, Lei X, Li P, Mi D, Ren L, Guo L, Guo R, Chen T, Hu J et al: Author Correction: Characterization of spike glycoprotein of SARS-CoV-2 on virus entry and its immune cross-reactivity with SARS-CoV. Nat Commun 2021, 12(1):2144.

50. Tseng SH, Lam B, Kung YJ, Lin J, Liu L, Tsai YC, Ferrall L, Roden RBS, Wu TC, Hung CF: A novel pseudovirus-based mouse model of SARS-CoV-2 infection to test COVID-19 interventions. J Biomed Sci 2021, 28(1):34.

51. Yan R, Cai D, Liu Y, Guo H: Detection of Hepatitis B Virus Particles Released from Cultured Cells by Particle Gel Assay. Methods Mol Biol 2017, 1540:193-202.

52. Yeh YT, Gulino K, Zhang Y, Sabestien A, Chou TW, Zhou B, Lin Z, Albert I, Lu H, Swaminathan V et al: A rapid and label-free platform for virus capture and identification from clinical samples. Proc Natl Acad Sci U S A 2020, 117(2):895-901.

53. Chin AWH, Chu JTS, Perera MRA, Hui KPY, Yen HL, Chan MCW, Peiris M, Poon LLM: Stability of SARSCoV-2 in different environmental conditions. Lancet Microbe 2020, 1(1):e10.

54. van Doremalen N, Bushmaker T, Morris DH, Holbrook MG, Gamble A, Williamson BN, Tamin A, Harcourt JL, Thornburg NJ, Gerber SI et al: Aerosol and surface stability of HCoV-19 (SARS-CoV-2) compared to SARS-CoV-1. medRxiv 2020.

55. van Doremalen N, Bushmaker T, Munster VJ: Stability of Middle East respiratory syndrome coronavirus (MERS-CoV) under different environmental conditions. Euro Surveill 2013, 18(38).

56. Chan SK, Du P, Ignacio C, Mehta S, Newton IG, Steinmetz NF: Biomimetic Virus-Like Particles as Severe Acute Respiratory Syndrome Coronavirus 2 Diagnostic Tools. ACS Nano 2021, 15(1):12591272.

57. Ma Y, Mao G, Wu G, Chen M, Qin F, Zheng L, Zhang XE: Dual-Fluorescence Labeling Pseudovirus for Real-Time Imaging of Single SARS-CoV-2 Entry in Respiratory Epithelial Cells. ACS Appl Mater Interfaces 2021, 13(21):24477-24486.

\section{Figures}


a

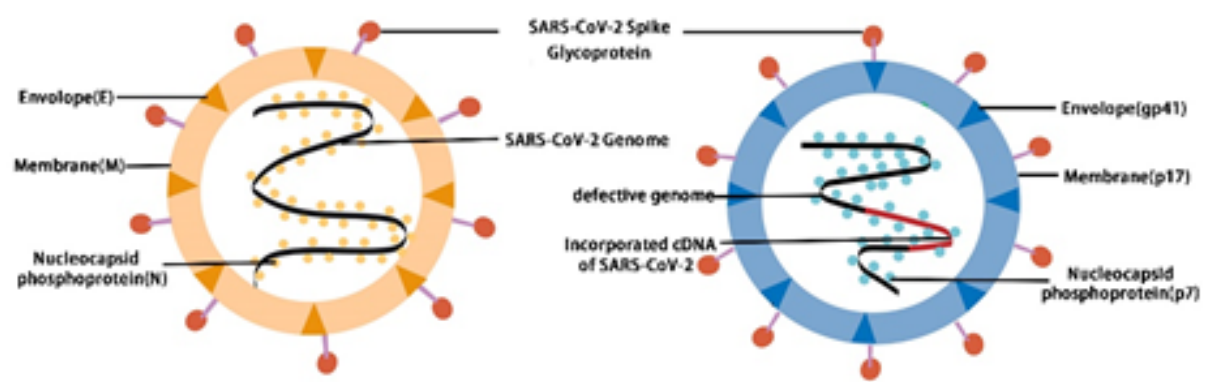

SARS-CoV-2

SARS-CoV-2 Pseudovirus

b

c

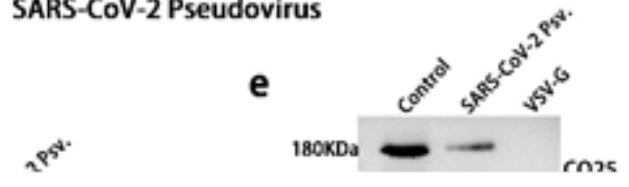

\section{Figure 1}

Construction of pseudo-SARS-CoV-2 virus and screening of specific antibodies directed to spike proteins.

a. Structures of SARS-CoV-2 and the SARS-CoV-2 pseudovirus. b. Infectivity of SARS-CoV-2 pseudovirus. HEK-293FT-hACE2 cells transduced with VSV-G encoding GFP were used as a positive control. c. Detection of SARS-CoV-2 S protein incorporated in lentivirus and analyzed via western blotting. The SARS-CoV-2 S protein expressed by $293 \mathrm{~T}$ cells transfected with vectors encoding the wild-type SARS-CoV$2 \mathrm{~S}$ glycoprotein was used as a positive control. $\mathbf{d}$. Detection of cDNA synthesized and cloned in SARSCoV-2 lentivirus via RT-qPCR using a 2019-nCoV nucleic acid detection kit (Sansure Bio, China). The VSV pseudotype virus was prepared using the same procedure and used as a negative sample. e. Identification of potential antibodies binding to the intact virus particle via western blot with the lysate of SARS-CoV-2 pseudovirus after heating for $10 \mathrm{~min}$ at $100^{\circ} \mathrm{C}$. The SARS-CoV-2 S protein expressed via 293T cells transfected with vector-encoded wild-type SARS-CoV-2 S glycoprotein used as a control. f. Identification of potential antibodies binding to the intact viral particle through the particle gel with 
pseudovirus resuspension. The VSV pseudotype virus was prepared suing the same procedure and used as a negative control.

\section{Figure 2}

Establishment of immunocapture-based SARS-CoV-2 pseudovirus detection platform. a. Flow diagram of immunocapture-based SARS-CoV-2 pseudovirus detection platform. b. Protein concentration of carboxyl magnetic bead-antibody complexes following conjugation evaluated in a BCA assay. c. Particle size analysis of carboxy magnetic beads (MB) and magnetic beads coupled with a CQ25 antibody (MB-CQ25) $(\star \star \star \star P<0.0001)$. d. Optimization of the antibody required for conjugation with beads. Carboxyl magnetic beads coupled with a CQ25 antibody and corresponding supernatant were detected using SDS-PAGE. e. SARS-CoV-2 pseudovirus captured via carboxyl magnetic beads coupled with a CQ25 antibody was detected using a viral particle gel assay with anti-HIV1 P24 antibodies. f. Multiple viruses captured via CQ25 antibody-coupled carboxyl magnetic beads were detected using qRT-PCR with a 2019-nCoV nucleic acid detection kit (Sansure Bio). 


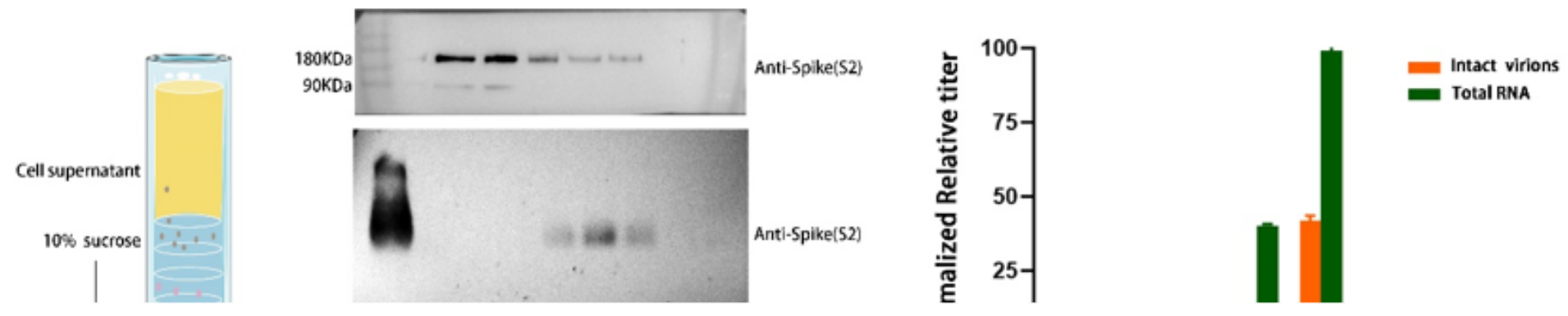

\section{Figure 3}

Detection target of immune molecular method is only intact virus particles. a. Levels of spike glycoprotein of SARS-CoV-2 pseudovirus in each gradient fraction analyzed using the western blot and viral particle gel methods, respectively. b. Levels of F1ab gene of SARS-CoV-2 pseudovirus in each gradient fraction analyzed via qRT-PCR and immunomolecular assay, respectively. c. Infectious activity corresponding to different titers of complete virions

\section{Figure 4}

Validation of immunomolecular assay for intact SARS-CoV-2 particles. a. Linear regression for the assay. When the SARS-CoV-2 pseudovirus titer ranged between $6 \times 10^{2}$ and $6 \times 10 \otimes \mathrm{TU} / \mathrm{mL}$, there was a linear relationship between the quantification $\mathrm{Cq}$ value and its titer (log-transformed) in the immunomolecular assay. $y=-2.537 x+40.02, R^{2}=0.99$. b. Specificity of the assay. Twenty-four of the carboxyl magnetic beads with CQ25 antibody complexes (MB-CQ25) and 24 captured pseudovirus samples were used to 
evaluate the assay specificity. ${ }^{\star \star \star *} \mathrm{P}<0.0001$. c. Interference from HBV supernatant from AD38 cells and patient serum with different titers of HBV. $\mathbf{d}$. SARS-CoV-2 pseudovirus stability under different conditions. Viruses were applied to copper, aluminum, paper, and plastic maintained at $21-23{ }^{\circ} \mathrm{C}$ and $40 \%$ relative humidity over 7 days. The titer of viable virus was expressed as $\log _{10}$-tranformed. Plots show the means and standard errors (I bars) of three replicates.

\section{Supplementary Files}

This is a list of supplementary files associated with this preprint. Click to download.

- Additionalfile1.docx

- graphicalabstractimage.png 